\title{
A PRODUÇÃO DE QUEIJOS NO SERTÃO SERGIPANO TROCA DE MÃOS: UMA QUESTÃO DE GÊNERO
}

\section{The production of cheese in Sertão Sergipano exchanges hands: a matter of gender}

\author{
Sônia de Souza Mendonça MENEZES ${ }^{1}$ \\ Maria Geralda de ALMEIDA ${ }^{2}$
}

\begin{abstract}
RESUMO
O nosso propósito neste estudo é apresentar as transformações ocorridas no meio rural do Sertão Sergipano do São Francisco no âmbito do sistema agroalimentar, destacando a questão de gênero no processo da produção de queijos. Com a inserção de políticas públicas foram introduzidas novas práticas proporcionando um acelerado desmatamento da vegetação original a caatinga. Implantam-se gramíneas resistentes à estiagem reduzindo-se as atividades agrícolas como a produção de alimentos: feijão, mandioca e o milho. Expande-se a pecuária alicerçada pelos recursos financeiros liberados pelo "Estado" na busca incessante para concretizar a modernização da agricultura. Paralelamente às alterações no meio ambiente, surgem mudanças no âmbito das relações sociais e nas práticas culturais. Tradicionalmente os agricultores familiares tinham a produção de leite destinada ao auto-consumo sob a forma in natura ou produzindo derivados a exemplo do queijo e manteiga caseira sob a responsabilidade das mulheres. Com o avanço da pecuária essa atividade transforma-se passando a ser de responsabilidade do sexo masculino em espaços exclusivos, surgem novos tipos e são construídas redes de comercialização.
\end{abstract}

Palavras-chave: identidade cultural; gênero; pecuária; políticas públicas.

\begin{abstract}
We aim at changing the rural areas of the Sertão Sergipano of San Francisco under the food system by highlighting the issue of gender in the process of the production of cheese. With the inclusion of public policies, new practices were introduced to provide a rapid deforestation of the original vegetation caatinga. Grasses are resistant to estiagem while reducing as agricultural activities as the production of foods: beans, cassava and maize. It expands to livestock by building financial resources released by the "state" in incessant search to achieve the modernization of agriculture. Besides the changes in environment, changes occur in the context of social relations and cultural practices. Traditionally the family farmers had to produce milk intended for self-consumption in the form in natura or producing derivatives such as cheese and homemade butter on the responsibility of women. With the advancement of livestock, this activity turns into a male work, and new types of networks start in the market.
\end{abstract}

Keywords: cultural identity; gender; livestock; public policies. 
MENEZES, S. de S. M.; ALMEIDA, M. G. A produção de queijos no Sertão Sergipano...

\section{INTRODUÇÃO}

O nosso propósito neste estudo é apresentar as transformações ocorridas no meio rural do Sertão Sergipano do São Francisco no âmbito da produção agroalimentar, enfocando a questão de gênero no processo de elaboração dos derivados do leite.

A partir da década de 1970 expande-se a pecuária alicerçada pelos recursos financeiros liberados pelo "Estado" na busca incessante para concretizar a modernização da agricultura sertaneja.

Paralelamente ocorrem alterações no meio ambiente, em face do avanço das atividades pecuaristas surgindo mudanças no âmbito das relações sociais e culturais proporcionando paulatinamente o êxodo rural e as mudanças nas práticas culturais.

Tradicionalmente os agricultores familiares utilizavam a terra para a produção de alimentos e a criação de gado leiteiro. A produção de leite destinava-se ao auto-consumo sob a forma in natura ou produzindo derivados a exemplo do queijo e manteiga caseira sob a responsabilidade das mulheres. Com as alterações no sistema produtivo esta atividade passa a ser de responsabilidade do homem. São articulados espaços exclusivos para a produção deste alimento surgem novos tipos e são construídas redes de comercialização. A tradição sertaneja da produção é mantida, no entanto, em outras mãos. Para desvendar essas alterações foram realizadas as leituras da abordagem cultural nos textos de Claval, Paul(1999), Almeida (2005), Bonnemaison, J. Cambrezy (1996), Haesbaert $(1999,2004)$, entre outras ladeadas por pesquisa de campo com os atores sertanejos. Refletir sobre essas alterações consiste no objetivo deste artigo.

\section{IDENTIDADE SERTANEJA: PECUÁRIA DOMÍNIO DO HOMEM/PREPARO DOS ALIMENTOS DOMÍNIO DA MULHER}

O meio rural apresenta-se como um universo heterogêneo no qual a agricultura familiar desempenha um importante papel na produção de alimentos e na criação de outras funções. Conhecer essas diversidades torna-se algo instigante e elementar para o estudo do território sertanejo. Território considerado a partir das relações existentes entre aqueles que têm uma identidade territorial com o mesmo, e consiste no resultado de uma apropriação simbólica-expressiva do espaço, sendo portador de significados e relações simbólicas. Para (ALMEIDA 2005, p. 338) o território é "resultado da valorização e da apropriação do espaço pelos seus grupos sociais. Esse território é visto como local de vivência e confrontação das manifestações" [...]. Corroborando com o pensamento de Almeida (2005), Dias (2005, p. 59) argumenta que o território "carrega uma dupla dimensão: os atributos espaciais-contiguidade e dispersão; e os atributos simbólicos-memória e identidade coletiva". O território expressará práticas e representações culturais impregnados de atributos simbólicos a exemplo da memória e da identidade.

Nesse sentido, ao analisar o meio rural sertanejo buscou-se estudar as suas práticas e a simbologia que envolve as atividades econômicas resultando na apropriação do meio pelos homens. Buscou-se identificar as questões de gênero que envolve homens e mulheres destacando a maneira como eles concebem e vivem no meio sertanejo destacando as transformações ocorridas nas atividades agroalimentares. Conforme Brandão (1999, p.14) "o meio natural é o cenário de embates entre os homens, através das suas relações práticas e simbólicas sempre providas de 'teias e tramas' dos significados vividos entre os atores sociais". Investigar os emanharados das representações torna-se imprescindível para o entendimento do contexto atual. Para tanto, buscou-se priorizar as pesquisas de campo e estudos realizadas no/ou sobre o território sertanejo. Nessa busca deparamo-nos com as atividades pecuaristas uma herança cultural que permeia a identidade sertaneja. Discutindo a noção de identidade Castells (2000, p. 22) entende como "um processo de construção de significados com base em um atributo cultural ou em um conjunto de atributos culturais inter-relacionados, $\mathrm{o}(\mathrm{s})$ qual(is) prevalece $(\mathrm{m})$ sobre outras fontes de significados". Tal atividade está arraigada no modo de vida da população local sendo manifestada nos setores econômico, social e cultural. Ao discutir a identidade territorial sertaneja faz-se necessário adentrar-se na história da ocupação humana nessa área tentando compreender as razões da preservação do sentimento de pertencimento, arraigados no sertanejo, cristalizado nas atividades econômicas do meio rural.

Reportando aos estudos realizados por Andrade (1986) e Diniz (1996), a ocupação das áreas sertanejas em Sergipe, iniciou-se no século XVI com a doação de grandes e pequenas glebas de terras pela coroa Portuguesa, visando firmar a posse, então ameaçada pelas invasões holandesas. A dimensão dessas glebas de terras, isto é, das sesmarias, variava de acordo com as possibilidades de sua utilização econômica, como também por sua localização e facilidade de acesso. A pecuária praticada em grandes áreas permitiu a formação de explorações extensas, uma vez que o gado 
MENEZES, S. de S. M.; ALMEIDA, M. G. A produção de queijos no Sertão Sergipano...

era criado solto, sem grandes cuidados. Essa atividade apresentava-se importante na complementação da produção de açúcar, suprindo a demanda de animais para os engenhos e na alimentação da população litorânea.

Embora tenham participado outras categorias na ocupação, o Sertão tem, no vaqueiro, um dos agentes precursores do povoamento, como salienta Diniz (1996, p.52) "utilizando-se da quarteação, acabou por se transformar em criador, dando origem a uma estrutura de pequenos pecuaristas que persiste até os dias atuais".

Nesse período, além da criação de gado, os agricultores familiares no sertão, dedicavam-se aos cultivos de milho, feijão, mandioca e algodão, abastecendo as grandes propriedades e a população urbana que crescia. Para tanto, aqueles que não possuíam área suficiente estabeleciam com o grande proprietário uma relação indireta no uso da terra pagando em rendatrabalho e/ou produto. Quando os grandes proprietários não cediam a terra, os trabalhadores transformavam-se em posseiros, ocupando novas áreas. No entanto, a produção de alimentos não se constituiu na atividade mais importante do sertão, como destaca (ANDRADE, 1986, p.155):

a agricultura não foi a atividade principal; desenvolveuse mediocremente à sombra dos "currais", devido à grande distância que separava aquela zona do litoral e ao elevado preço que os gêneros atingiam após o transporte por dezenas de léguas.

No final do século XVIII e no século XIX, houve uma grande expansão da lavoura do algodão, sobretudo no período da Guerra da Secessão nos Estados Unidos. Essa cultura presente nos estabelecimentos do agricultor familiar desperta o interesse também do grande proprietário. Percebendo que a rama do algodão, juntamente com a palha do milho, poderia constituir-se em uma ração suplementar para o gado nos meses mais secos, passou a ceder terra aos trabalhadores desprovidos desse bem em troca do restolho dessas culturas. Conseqüentemente, houve uma revitalização da pecuária, surgindo novas perspectivas para o sertão. A cotonicultura, juntamente com a pecuária, proporcionou o surgimento de vários centros urbanos no sertão sergipano.

Após o período de crise do algodão, o agricultor familiar continuou a plantar o mesmo cultivo consorciado, enquanto os grandes proprietários se dedicaram à pecuária de forma praticamente exclusiva.

A pecuária, apesar de ser uma atividade importante, até a metade do século XX apresentava-se ainda pouco intensiva, sendo os bovinos criados soltos, pouco modificando a vegetação nativa do sertão. Tradicionalmente na sociedade nordestina há uma definição da ocupação dos espaços pelo homem. O poder exercido pelo sexo masculino delimita como seus territórios àqueles rentáveis economicamente a exemplo dos campos de cultivo e ou/as pastagens, áreas alheias à sua residência. Enquanto isso, o domínio do lar e suas proximidades constituíam no território da mulher.

Definido o seu território são atribuições do sexo feminino a tarefa de transformar os produtos do roçado ou os mantimentos em alimentos comestíveis. Woortmann e Woortmann (1997, p. 37) afirmam que contrapondo a posição masculina, a mulher ocupa um lugar determinado: "a casa, núcleo simbólico da família". Em consonância com o pensamento desses autores (CLAVAL 1999, p. 85) afirma:

a carga afetiva da casa é forte. Ela aparece como um território onde a presença feminina é particularmente forte. Ao homem cabe controlar os espaços produtivos externos à casa, cabe à mulher o governo da mesma.

No entanto, ao definir o trabalho feminino de forma quase exclusiva dentro dos espaços do lar ou nas suas cercanias suas atividades são consideradas geralmente como "ajuda" subtraindo o valor do trabalho realizado nas tarefas domésticas sendo essas pouco valorizadas. Desse modo o processo de trabalho consiste em discutir a produção de gênero.

As mulheres sertanejas estiveram reclusas ao lar expandindo o seu domínio em alguns períodos no campo. Responsáveis pela alimentação da família aproveitavam das potencialidades existentes no meio para elaborarem iguarias até a década de 1970 em virtude da inexistência de produtos industrializados no meio rural.

Os pratos típicos da culinária sertaneja apresentavam simplicidade, consistindo segundo Castro (1969), isentos da influência da cultura negra e índia, dominados por traços portugueses e ou de mamelucos, apresentando algumas semelhanças com a alimentação árabe.

Pesquisando sobre a culinária sertaneja (CASTRO 1969, p. 176) destaca os trabalhos de Câmara Cascudo, Nina Rodrigues e Cleto Seabra Veloso nos quais são evidenciados a importância e o domínio da cultura do milho base alimentar do sertanejo. Tais autores destacam as variadas formas de uso do milho enfatizando que quase sempre esse produto é consumido juntamente com o leite "numa combinação feliz". O leite também é utilizado na dieta alimentar sob várias outras formas 
MENEZES, S. de S. M.; ALMEIDA, M. G. A produção de queijos no Sertão Sergipano...

a exemplo da coalhada fresca ou escorrida, ou sob a forma de derivados, manteiga e queijo. Principalmente manteiga fresca e requeijão, tipo de queijo gordo de que os sertanejos fazem largo uso cru ou assado.

A prática cultural da elaboração desses produtos derivados do leite foi repassada pelos antepassados ao domínio feminino consistindo o interior das residências o território destinado à sua produção. Esse saber-fazer interiorizado pelas mulheres objetivava quase que exclusivamente a alimentação da própria família.

Ao receber visitas de parentes, amigos e compadres que habitavam nas áreas urbanas distantes do sertão fazia parte da tradição sertaneja presenteá-los no momento da partida com um queijo de coalho ou um requeijão caseiro. Ainda quando um sertanejo visitava seus parentes ou amigos nas áreas urbanas levava consigo um queijo como lembrança dos seus familiares. Fato esse recebido com grande alegria pelos receptores possibilitando na apreciação de tal ingrediente recordar sua alimentação ou dos momentos que desfrutava do meio rural ou da sua infância caso fosse o mesmo sertanejo. Prática ainda hoje evidenciada nestas áreas.

Esses alimentos passavam por um processo de maturação podendo ser consumido após várias semanas da produção. Utilizavam uma quantidade de sal objetivando à conservação do alimento, apresentando assim um produtor com um teor de sal acentuado sobretudo o queijo de coalho.

Para conservar esses derivados, Câmara Cascudo (2004, p. 428-429) ressalta que ao vivenciar o Sertão Velho ele conhecia os processos de conservação de carnes, queijos e cereais, os quais eram "enfurnados nas meias-trevas das camarinhas suspensos em jiraus. As garrafas com manteiga ficavam em lugar fresco e de pouca luz". Esses produtos processados pelas mãos femininas não recebiam nenhuma ajuda masculina, uma vez que a quantidade de leite processada era pequena do próprio estabelecimento, e cozinha não "consistia em lugar de homem".

A pecuária leiteira não apresentava elevada produtividade uma vez que o gado era predominantemente tipo "pé duro" rústico de pequeno porte, alimentado com gramíneas naturais e além do consumo humano também o leite seria utilizado para a alimentação dos bezerros. Dessa forma, a quantidade utilizada para a produção dos derivados era pequena, salvo em períodos de invernos "bons" (com elevada pluviosidade), nesse caso as mulheres recebiam ajuda das filhas adolescentes.
Diferentemente das demais regiões produtora de leite e derivados no Brasil, o sertão nordestino em virtude das dificuldades nas vias de locomoção e a ausência de mercado consumidor o consumo desses produtos era feito localmente, resultando em uma dieta sertaneja detentora de excepcional valor nutritivo. Nesse sentido, (CASTRO, 1969, p.18) ao abordar a dieta sertaneja enfatiza:

Na carne de bode, leite e no queijo do sertão estão boa parte das justificativas biológicas que respaldam a hoje famosa frase de Euclides da Cunha, que o "sertanejo é antes de tudo, um forte". Realmente, só um povo forte pode "exibir esta força, esta resistência surpreendente às fadigas e às vicissitudes mais exacerbadoras, esta disposição incansável ao trabalho, esta constituição férrea, que o torna sobranceiro às intempéries, aos reveses, às endemias, e o leva a cometimentos titânicos.

Comparando a dieta sertaneja às demais regiões produtoras de leite do país, Castro (1969) esclarece que esse produto e seus derivados nas regiões sudeste e sul são destinados ao comércio, sobretudo, para o abastecimento das cidades populosas facilitadas pelas vias de escoamento e comercialização eficientes. Contrapondose a realidade nordestina os derivados nas regiões sudeste/sul não constituem elemento essencial na dieta dos trabalhadores das áreas produtoras, provocando uma dieta alimentar mais pobre que a sertaneja.

Essa configuração do sertão sergipano perdura até a década de 1960 apresentando as relações destacadas sem alterações.

\section{A REFUNCIONALIZAÇÃO DO MEIO RURAL OU ADAPTAÇÃO DO SERTANEJO PRESERVANDO SUA IDENTIDADE?}

A partir da década de 1970, a pecuária em Sergipe, localizada principalmente no agreste e sertão, alçada prioritariamente por uma agricultura familiar, tem seu crescimento acelerado. Esse crescimento é uma consequência de alguns fatores favoráveis como: melhores estradas, clima propício às pastagens, menor incidência de doenças no rebanho bovino e uma política de crédito agrícola voltada principalmente para a região semi-árida por meio dos Projetos PROTERRA, POLONORDESTE e SERTANEJO. Câmara Cascudo (2005, p. 12) destaca: "o sertão se modifica rapidamente. Uniformiza-se banaliza-se".

As linhas de atuação do PROTERRA - Programa de Redistribuição de Terras e de Estímulos à Agroindústria do Norte e Nordeste - consistiam no apoio ao campe- 
MENEZES, S. de S. M.; ALMEIDA, M. G. A produção de queijos no Sertão Sergipano...

sinato, com pequenos estabelecimentos ou desprovido de terra por meio da desapropriação, e também com a introdução de programas de modernização agropecuária e agro-industrial com liberação de financiamentos a longo prazo e juros baixos. Entretanto, esse programa revelou-se como uma fonte de crédito rural em detrimento da distribuição de terras no Nordeste.

Dessa forma, o programa, que objetivava a distribuição de terras, aplicou a maior parte dos seus recursos na inovação e modernização dos grandes e médios estabelecimentos, proporcionando a expulsão de parte da população rural sem terra.

Sorj (1986 p.104) ainda, analisando a atuação do POLONORDESTE-1974 - Programa de Desenvolvimento de Áreas Integradas, reafirma sua idéia ao dizer que esse se transformou em um mecanismo de fortalecimento dos grandes e médios produtores, reforçado pela implementação de projetos de modernização agrícola, provocando o crescimento do êxodo rural, em virtude da expansão pecuarista na área.

O Projeto SERTANEJO - Programa Especial de Apoio ao Desenvolvimento da Região Semi-Árida do Nordeste, foi criado em agosto de 1976/1986. Visava interferir nessa área nordestina, objetivando tornar a sua agricultura resistente às secas e explorar suas possibilidades de desenvolvimento. Contribuiu para o crescimento da pecuária, atuando na viabilização das reservas alimentícias para os animais nos períodos de estiagem, funcionando como linha de crédito destinada a investimentos fixos, semifixos e de custeio. Ainda, desenvolveu ações que proporcionaram a implantação de pastagens, mecanização e tração animal, conservação de açudes e solos. Assim, de forma crescente foram introduzidas na área sementes selecionadas como a do buffel (Cenchrus ciliaris), pangola (Digitaria decumbens S) e a brachiária (Brachiária decumbens), além da utilização de máquinas agrícolas modernas (como tratores) na aração das terras.

Com a introdução dessas mudanças na agricultura e o incremento da pecuária, os proprietários rurais utilizam-se de reduzida mão-de-obra no trato com o gado. Na formação das pastagens plantadas, recorremse à renda-trabalho para semear o capim, cedendo a terra por um a dois anos aos camponeses, recebendo em troca o pasto formado. Assim esse trabalhador, semterra ou com terra, insuficiente passa a deslocar-se em busca de novas terras.

Aliando-se a esses fatores, têm-se os efeitos da legislação trabalhista, que muito onera os empregadores na manutenção de trabalhadores residentes, optando esses, desse modo, pelo emprego dos temporários. Além dessas causas, a cidade atrai o homem do campo, graças ao desenvolvimento industrial e à maior oferta de serviços; entretanto, a oferta não se apresenta compatível com a demanda de postos de trabalho, em virtude da velocidade do crescimento populacional urbano. Em conseqüência a essa acentuada urbanização nos anos 1970, há um incremento na demanda do leite e uma maior valorização desse produto. O escoamento é facilitado pelas novas e pavimentadas rodovias que integram com rapidez as áreas produtoras aos recentes mercados. Em contrapartida, tem-se a decadência do cultivo do algodão nesse estado por causa da praga do bicudo- Anthono-musgandis, ficando o camponês sem um produto de valor comercial. Desse modo, há um crescimento na pecuária leiteira, principalmente nos estabelecimentos pertencentes aos agricultores familiares do sertão sergipano, com produto que consegue inserção no mercado. Nesse contexto, a pequena unidade de produção pertencente aos agricultores familiares, que se dedicava à lavoura de milho, feijão, mandioca e algodão consorciados, transforma a pequena unidade de produção, especificamente os espaços de seus cultivos, em pastagens direcionadas para o gado leiteiro, na busca da sobrevivência. A permuta do cultivo agrícola pela pastagem decorreu do rendimento mais estável e seguro da pecuária, o que viabiliza a persistência familiar, criando dessa forma uma estratégia de reprodução. Woortmann (1995, p. 286) ao estudar municípios sertanejos em Sergipe faz uma análise da relação entre esses agricultores e sua pequena propriedade:

No sítio o gado é "criação" e corresponde a uma atividade meio. Seu significado é basicamente o de uma reserva de valor; garantia contra os efeitos da seca, à qual ele resiste mais que a lavoura; o de uma forma de acumulação ou de poupança, destinada à aquisição de terra, inclusive para possibilitar a herança.

A atividade pecuarista além de ser um "capital" para uso em caso de necessidades, contribuiu para o crescimento da migração de trabalhadores em virtude da relação capital-trabalho que os empurra para os centros urbanos, surgindo o chamado exército de reserva. O capital industrial investe e atrai trabalhadores da zona rural e, a sua expansão se dá associada à formação do latifúndio. Nesse ínterim, os agricultores com até 50 hectares, em decorrência das intempéries climáticas, da crise do cultivo da cotonicultura e para resistirem às ofertas norteadoras de compra e venda de suas terras, transformam também seus estabelecimentos em pastagens. Os agricultores com o seu saber refletem as propostas que são apresentadas e criam as suas estratégias conduzidas pela sua identidade sociocul- 
MENEZES, S. de S. M.; ALMEIDA, M. G. A produção de queijos no Sertão Sergipano...

tural, caracterizada pela sua concepção sobre a terra como um lugar de vida e do trabalho. (WANDERLEY, 2001). Essa estratégia de reprodução contribuiu também para a expansão da atividade pecuarista e rompe com a tradição da exclusividade do grande produtor responsabilizar-se por essa criação. Contrariando os prognósticos que enfatizavam o desaparecimento do agricultor familiar, ele sobrevive ativo contrapondo-se ao paradigma da empresa rural que objetiva expandir seus cultivos absorvendo muitas vezes as terras dos pequenos produtores.

Nesse contexto, a pecuária leiteira se apresenta como uma estratégia para a sustentabilidade do agricultor familiar criando uma nova forma de renda semanal, por meio da comercialização do leite. Tal fato pode ser comprovado por informações censitárias de 1970, 1985 e 1995/1996. Refletindo as conseqüências das públicas direcionadas a expansão pecuarista e a mudança no uso da terra nos estabelecimentos familiares observa-se um crescimento de $16,6 \%$ entre 1970 e 1995/1996 no número de vacas ordenhadas na microrregião do Sertão Sergipano do São Francisco ${ }^{3}$. No último censo, essa microrregião totaliza um percentual superior a 37\% de vacas ordenhadas no estado de Sergipe, estando esses concentrados nos estabelecimentos familiares que dedicam com exclusividade à criação destes animais.

Na microrregião, foi verificado um aumento de 25,5\% no volume de leite produzido, no período de 1970 a 1996, absorvendo, no último censo, mais de $40 \%$ do total produzido no estado, constituindo a maior bacia leiteira de Sergipe. Observa-se que essa microrregião apresenta um percentual de crescimento superior na produção de leite-25,5\%, comparando com o crescimento no total do número de vacas ordenhadas-16,6\% o que significa, que ocorreu um melhoramento no padrão genético dos animais.

Corroborando com a discussão sobre as alterações no uso da terra, (DEBEUX JÚNIOR 1998, p. 65) afirma que a pecuária leiteira deve ser tratada, no caso da região Nordeste, relacionando-a a questão social como já foi discutida as razões anteriormente; ele enfatiza: "A atividade leiteira deve ser vista sob um prisma social em algumas regiões semi-áridas do Nordeste, contribuindo para aumentar a oportunidade de ocupação da mão-de-obra e remuneração do trabalho familiar sendo mais estável que a agricultura de sequeiro".

Ao analisar essas informações censitárias observa-se que as atividades agrícolas sobretudo a pecuária expande na região do sertão sergipano. Com o crescimento da pecuária leiteira, surgem novas atividades, construídas a partir do aumento da oferta do leite existente na região, transformando-o em derivados nas pequenas unidades de produção. Tal evidencia vai ao encontro do posicionamento de Wanderley (2001, p. 38) ao afirmar que "a agricultura ainda é, e será por muito tempo, a atividade principal, a fonte principal de ocupação e renda, a base para a criação de novas alternativas econômicas e para o desenvolvimento de atividades de transformação e comercialização". Nesse contexto, verifica-se que os atores organizam diferentes formas de aproveitamento dos recursos existentes no território contribuindo para a sustentabilidade da exploração da qual participa, fato esse comprovado na microrregião do Sertão do São Francisco Sergipano.

Observou-se nessa região que em alguns estabelecimentos agrícolas, o núcleo familiar constitui uma pequena empresa, de caráter informal. Essas são denominadas de fabriquetas de queijo constituindo em verdadeiros mananciais de habilidades empreendedoras, a partir do saber-fazer, a exemplo das inovações na produção de novos tipos de derivados de leite e na criação de equipamentos. (WOORTMANN; WOORTMANN, 1997, p.177-178) sobre o saber-fazer camponês esclarece:

O saber-fazer camponês não é estático. Através de gerações ele acumulada experiência e pode, em certos momentos, retomar técnicas desenvolvidas no passado, deixadas como que "entre parênteses" na memória do grupo[...]. . Ao mesmo tempo que resgatam o passado, introduzem inovações[...]

Essas pequenas unidades de produção são também estimuladoras de geração de renda e postos de trabalho. Entretanto, o processamento dos derivados muda de mãos, muda de significado, outrora, a produção de queijos exclusiva do domínio feminino termina o seu ciclo de vida [...] longo processo de trabalho, reclusas ao ambiente residencial. Ao processar agora grandes quantidades, as mulheres repassam o saber-fazer aos seus filhos ou ao seu esposo/companheiro. Dessa forma, repassando os conhecimentos sua cultura e tradição continua viva e um produto da sua dieta atinge novos mercados.

O processo de trabalho produz o gênero comprovado no momento em que referem-se a essa "nova" produção de queijos em fabriquetas. Quando indagados sobre as mudanças os homens as associam

3 Microrregião do Sertão Sergipano do São Francisco é formada pelos seguintes municípios: Canindé do São Francisco, Poço Redondo, Monte Alegre de Sergipe, Porto da Folha, Gararu, Feira Nova e Graccho Cardoso, Nossa Senhora da Glória. 
MENEZES, S. de S. M.; ALMEIDA, M. G. A produção de queijos no Sertão Sergipano...

às questões de produção/quantidade $X$ sexualidade, destacando a mulher como "sexo frágil" na condução de grandes quantidades de leite. Nesse caso, eles argumentam que o leite processado não condiz exclusivamente ao produzido dentro da propriedade mas, adquirido também das propriedades vizinhas, e/ou das mais distantes. "Não pode a mulher ocupar tal serviço que requer muita força. Além disto em um ambiente fora de casa com outros homens, esta é uma função designada somente ao sexo masculino". Observa-se que existe o domínio do preconceito relacionado ainda ao território que deve ser ocupados pelas mulheres, lugar delas ainda é a casa, mesmo observando que as fabriquetas estão localizadas nas proximidades da sua residência. No entanto, por outro lado não há disputa no território ou luta pelo poder uma vez que anteriormente eram as mulheres as responsáveis pelos derivados agora, são seus filhos e esposo e/ou conjuntamente com outros parentes. Para elas, significa uma nova forma de ocupação repassada para o âmbito familiar uma vez que há uma carência de trabalho no sertão. Tal fato pode ser identificado como o exercício do poder simbólico definido por (BOURDIEU, 1989, p. 7-8) "poder invisível o qual só pode ser exercido com a cumplicidade daqueles que não querem saber que lhe estão sujeitos ou mesmo que o exercem". Observa-se um estado de conformismo, apatia das mulheres sem reivindicação existe uma aceitação do repasse da "tradição queijeira inovada". Nesse sentido, (HOBSBAWM,1984, p. 1213) esclarece: "inventam-se novas tradições quando ocorrem transformações suficientemente amplas e rápidas tanto do lado da demanda quanto da oferta". Observa-se que há uma necessidade incitando essas famílias a exercerem ou criarem alternativas externas à agropecuária ou aproveitarem desse potencial adaptando o saber-fazer típico existente na área. Ao mesmo tempo há um crescimento na demanda dos derivados para abastecer a população urbana predominante a partir da década de 1970 no estado de Sergipe ocupante das áreas litorâneas.

As fabriquetas de queijo são pequenas empresas comerciais, artesanais ou protoindustriais inseridas no mercado informal. Essas colaboram na diversificação das economias locais, surgindo um número considerável de lojas de produtos agropecuários e pequenas oficinas que criam equipamentos para a produção dos derivados e para o transporte da matéria-prima.

Esse sistema agroalimentar apresenta semelhança com o circuito inferior da economia existente nos espaços urbanos analisados por Milton Santos (2004) nos quais as atividades estão com base simultanea- mente no crédito pessoal direto e no dinheiro líquido e, o lucro diferentemente do circuito superior que objetiva a acumulação do capital, nesse circuito o objetivo primordial é a sobrevivência cotidiana das famílias. As atividades realizadas localmente mesmo estando articuladas regionalmente proporcionam o aumento da circulação do capital local. Tais características também são evidenciadas nessa atividade agroalimentar no meio rural sertanejo sergipano.

Essa atividade permite a consolidação dos agricultores, uma vez que absorve a produção de leite, sobretudo do agricultor familiar, constituindo alternativa única em vários municípios do Sertão Sergipano. Ainda são gerados postos de trabalho no transporte da matéria-prima, na produção e comercialização dos derivados, incorporando em parte, os filhos dos agricultores em uma área carente de trabalho e renda. Sob essa ótica, esta estratégia expressa a garantia da permanência no meio rural preservando a sua identidade cultural.

\section{CONCLUSÃO}

A dimensão das transformações ocorridas no Sertão Sergipano repercute não exclusivamente no meio-ambiente, mas, nas relações sociais e culturais. Com a expansão da pecuária por todos os tipos de estabelecimentos surgem "novas" atividades que contribui para a fixação do agricultor familiar. No entanto, ocorrem rompimentos na tradicional produção de queijos envolvendo a questão de gênero. As mulheres são excluídas do processo, do seu domínio. É de se esperar os diversos atritos!! No entanto, esses não ocorrem, a tradição foi mantida a mulher continua no seu território "de dentro" (casa), à medida que a atividade queijeira tornou-se rentável e deslocou-se do interior "para fora" das residências o homem controlador dos territórios externos torna-se o responsável pela produção. Ao repassar as técnicas os conhecimentos, à tradição da cultura sertaneja se mantêm. Ao discutir a cultura (CLAVAL, 1999, p. 64) esclarece:

A cultura designa o conjunto de savoir-faire, de práticas, de conhecimentos, de atitudes e de idéias que cada individuo recebe, interiorizando, modifica ou elabora no decorrer de sua existência. De uma geração a outra os conteúdos mudam, uma vez que o meio físico se modifica e é apreendido, expandido, explorado, organizado ou examinado com novos meios. [...] a cultura é um conjunto diversificado ao infinito e em constante evolução.

A partir das alterações implementadas no meio, os sertanejos mudam e recorrem ao saber-fazer tradicional incluem novas receitas, buscando continuar 
MENEZES, S. de S. M.; ALMEIDA, M. G. A produção de queijos no Sertão Sergipano...

sobrevivendo no seu território. Para tanto, trocam os atores a cultura sertaneja continua. O sertanejo têm ainda o queijo como elemento essencial na sua dieta e atualmente o fornece para os seus conterrâneos que vive/sobrevive nas cidades litorâneas possibilitando àqueles a manutenção de parte da sua identidade territorial.

\section{REFERÊNCIAS}

ALMEIDA, Maria G. de. Territórios e territorialidades. Revista da ANPEGE. Fortaleza, p. 103-114, 2005.

ANDRADE, Manoel C. de. A terra e o homem no Nordeste. 5. ed. São Paulo: Ed. Atlas, 1986.

BONNEMAISON, J.; CAMBREZY, L. Le Lien entre frontiers et identities. Geographie et Cultures. n. 20, p. 6-15, 1996.

BORDIEU, Pierre. O poder simbólico. Rio de Janeiro: Bertrand Brasil, 1989.

BRANDÃO, C. O afeto da terra. Campinas: Editora Unicamp, 1999.

CASCUDO, L. de C. História da alimentação no Brasil. 3. ed. São Paulo: Global, 2004.

CASTELLS, Manuel. O Poder da Identidade. Tradução: Klauss Brandini Gerhardt. v. II. 2. ed. São Paulo: Paz e Terra, 2000.

CASTRO, Josué de. Geografia da Fome: o dilema brasileiro: pão ou aço. 9. ed. São Paulo: Brasiliense. 1969. 332 p.

CLAVAL, Paul. La géographie culturelle. Paris: Nathan. 1995.

DEBEUX JÚNIOR, J. C. B. Cenário atual da produção leiteira pernambucana: caracterização e identificação de demandas tecnológicas. In: SEMINÁRIO IDENTIFICAÇÃO DE RES-
TRIÇÕES ECONÔMICAS E INSTITUCIONAIS AO DESENVOLVIMENTO DO SETOR LEITEIRO NACIONAL. REGIÃO NORDESTE. Anais... Fortaleza, p. 63-68,1998.

DIAS, Leila C. Os sentidos da rede: notas para discussão. In: DIAS, Leila C; SILVEIRA, Rogério L. L. (Orgs.). Redes, sociedades e territórios. Santa Cruz do Sul: Edunisc, 2005, p. 11-28.

DINIZ, José A. F. A condição camponesa em Sergipe - desigualdade e persistência da agricultura familiar. Aracaju: NPGEO, 1996.

HAESBAERT. Rogério. O mito da desterritorialização: do fim dos territórios a multiterritorialidade. Rio de Janeiro: Bertrand do Brasil, 2004.

. Identidades territoriais. In: ROSENDAHL, Z.; CORREA, R. L. Manifestações da cultura do espaço. Rio de Janeiro: Ed. UERJ, 1999, p.169-190.

HOBSBAWM. Eric. A invenção das tradições. Tradução Celina Cardim Cavalcanti. Rio de Janeiro: Paz e Terra, 1984.

SANTOS, Milton. O espaço dividido: os dois circuitos da economia urbana dos países subdesenvolvidos. 2. ed. São Paulo: Edusp, 2004.

SORG. B. Estados e classes sociais na agricultura brasileira. 2. ed. Rio de Janeiro, 1986.

WANDERLEY, M. de N. B. A ruralidade no Brasil moderno: por um pacto social pelo desenvolvimento rural. In: GIARRACCA, Norma (Copem.) Uma nueva ruralidad en América Latina? Buenos Aires, CLACSO, 2001, p. 31-44 (Coleccion grupos de Trabaho de CLACSO).

WOORTMANN, Ellen F. Herdeiros, parentes e compadres. São Paulo: Hucitec; Brasília: Edunb, 1995.

.; WOORTMANN, Klaus. O Trabalho da Terra: A lógica e a simbólica da lavoura camponesa. Brasília. Ed. UNB, 1997. 